\title{
Overexpression of Survivin-1, TAG-72 and HERC5 in patients diagnosed with hepatocellular carcinoma in the Black Sea coast geographical area
}

\author{
ANDRA-IULIA SUCEVEANU ${ }^{1 *}$, IOAN SERGIU MICU ${ }^{1 *}$, GABRIELA-IZABELA BALTATESCU $^{2 *}$, \\ LUCIAN CRISTIAN PETCU ${ }^{3}$, NICOLAE DOBRIN ${ }^{2}$, COSTEL BRINZAN $^{4}$, CORNELIA NITIPIR $^{5}$, \\ LAURA MAZILU $^{6}$, FLORIN BOTEA $^{7}$, VLAD HERLEA $^{8}$, FELIX VOINEA $^{9}$ and ADRIAN PAUL SUCEVEANU ${ }^{1}$ \\ ${ }^{1}$ Department of Gastroenterology, ${ }^{2}$ Research and Development Centre for The Morphologic and Genetic Study of \\ Malignant Pathology, ${ }^{3}$ Dentistry Faculty, Biophysics and Biostatistics Disciplines, and ${ }^{4}$ Doctoral School of Medicine, \\ 'Ovidius' University, 900527 Constanta; ${ }^{5}$ Department of Oncology, 'Carol Davila' University of Medicine and Pharmacy, \\ 050474 Bucharest; ${ }^{6}$ Department of Oncology, 'Ovidius' University, 900527 Constanta; \\ ${ }^{7}$ Liver Transplant and General Surgery Centre, ${ }^{8}$ Department of Pathology, 'Fundeni' Institute, 022328 Bucharest; \\ ${ }^{9}$ Department of Urology, 'Ovidius' University, 900527 Constanta, Romania
}

Received October 27, 2020; Accepted November 26, 2020

DOI: $10.3892 /$ etm.2021.9715

\begin{abstract}
Epidemiological data regarding hepatocellular carcinoma (HCC) report unsatisfactory morbimortality rates despite the global efforts to decrease the incidence and prolong patient survival. Current guidelines lack diagnostic biomarkers to better characterize patients with HCC. We aimed to validate the overexpression of Survivin-1, tumor-associated glyocoprotein 72 (Tag-72), and HECT and RLD domain containing E3 ubiquitin protein ligase 5 (HERC5) as tissue biomarkers for HCC characterization in patients from our geographical area and to standardize a local biomarker panel to be introduced in the current management guideline. Thirty samples of histologically confirmed HCC were compared to an equal number of samples of benign tumors in terms of Survivin-1, TAG-72, and HERC5 overexpression. Student's t-test, Mann-Whitney U test and Chi-square test were used to find differences between the two studied groups and to compare the categorical variables. The discriminative power of Survivin-1, Tag-72, and HERC5 overexpression was assessed using ROC curves. The multivariate linear regression analysis revealed that Survivin, Tag-72, and HERC5 were significantly overexpressed in older male patients, with $\alpha$-fetoprotein (AFP) $>200 \mathrm{ng} / \mathrm{dl}$, low
\end{abstract}

Correspondence to: Professor Andra-Iulia Suceveanu or Dr Ioan Sergiu Micu, Department of Gastroenterology, 'Ovidius' University, 124 Mamaia Boulevard, 900527 Constanta, Romania

E-mail: andrasuceveanu@yahoo.com

E-mail: micuioansergiu@yahoo.com

*Contributed equally

Key words: immunohistochemistry, overexpression, Survivin-1, Tag-72, HERC5, hepatocellular carcinoma serum albumin, as well as in patients with imaging features of portal thrombosis and ascites. The diagnostic performance of Survivin-1, Tag-72 and HERC5 tissue biomarkers for HCC characterization was superior to that of the gold-standard AFP. Our study results validate the overexpression of Survivin-1, Tag-72, and HERC5 as tissue biomarkers for HCC characterization in patients from our geographical region and could be standardized in the current HCC management guideline.

\section{Introduction}

Despite the great achievements obtained in the early detection of hepatocellular carcinoma (HCC) through screening programs and application of targeted therapies with protease inhibitors such as sorafenib, the incidence and the poor survival rate reported are still high, especially in endemic areas for hepatotropic viruses (HBV, HCV and HDV) such as southeastern Europe (1-4). Panels of biomarkers are standardized to help clinicians in their efforts to improve knowledge in terms of better HCC characterization for more efficient therapies. A single biomarker still used for HCC diagnosis or follow-up is $\alpha$-fetoprotein (AFP), which is considered as the gold standard of care. Yet, clinical evidence suggests that it does not help facilitate improvement in HCC progression, prognosis, or survival rates (5). In general, tumor cells present metabolic signatures compared to healthy cells, both at the tissue and bio-humoral levels. The detection of new tumor cell biomarkers, and their validation has presented new research goals for HCC characterization. Viral infections, alcohol abuse, dysmetabolic states [obesity, type 2 diabetes mellitus (T2DM), nonalcoholic steatohepatitis (NASH)], and other rare conditions causing subsequent chronic liver damage promote liver tumorigenesis through different mechanisms and this situation makes it difficult to standardize a panel of predictive biomarkers for HCC progression (6-9). Survivin-1, an anti-apoptotic protein modulated by the p53 
gene, presents overexpression in $70 \%$ of Asian HCC patients with chronic viral hepatitis in whom mutations of p53-gene are apparent (10). The overexpression of this tissue biomarker has not been studied in other research. It represents an opportunity to study Survivin-1 due to the similarity between risk factors for HCC occurrence in our patients and Asian patients-a vast majority being infected by hepatitis $\mathrm{B}, \mathrm{C}$, and D viruses. Tumor-associated glycoprotein 72 (TAG-72) is a mucin-like membrane complex considered to be a feasible biomarker for unfavorable prognosis of adenocarcinomas in general, with potential applicability in HCC $(11,12)$. HECT and RLD domain containing E3 ubiquitin protein ligase 5 (HERC5), a protein with a ligand role, activates the chemotaxis and the local infiltration with $\mathrm{T}$ lymphocytes, being considered a biomarker for predicting HCC recurrence, as well as the poor survival rates even for early stage $\operatorname{HCC}(13,14)$. In this scenario, we aimed to evaluate and validate the overexpression of Survivin-1, TAG-72, and HERC5 as tissue biomarkers for HCC characterization in patients from our geographical region and to standardize a local biomarker panel to be introduced in the current management guideline.

\section{Materials and methods}

Materials. Thirty liver specimens with a histopathological diagnosis of HCC (study group) and a similar number of liver tissue specimens of benign liver tumors (adenomas, HNF, regenerative nodules, and hemangiomas-control group) were selected from the Gastroenterology file database and Pathology Clinic registries from St. Apostle Andrew Emergency Clinical Hospital, Constanta and Fundeni Institute, Bucharest and compared in terms of Survivin-1, Tag-72, and HERC5 overexpression. All cases were registered in our databases in the last 3 years and 6 months (January 2017 to June 2020).

All cases histologically confirmed by pathologists from both clinics, were reinterpreted for the current study during the interval December 2019 to June 2020, and the immunohistochemistry study was conducted at the Research and Development Centre for the Morphologic and Genetic Study of Malignant Pathology (CEDMOG) and founded by 'Ovidius' University. The morphological features of the tumors were noted, establishing the histological type, the grade, and the stage of HCC based on the World Health Organization (WHO) Histological Classification for digestive tumors (15).

Demographic data of all patients (study and control group) providing the liver specimens, including age, sex, provenence, medical history, liver disease background-chronic viral infections with B, C, or D viruses, co-morbidities and laboratory parameters recorded at the time of hospital admission were obtained from the clinical files and are noted in Table I.

The Ethics Committee of Emergency Clinical Hospital St. Apostle Andrew of Constanta approved the study following European and local regulations (no. 32/22.11.2019).

Methods. For the immunohistochemical (IHC) assessment, the representative samples were chosen, and $4-\mu \mathrm{m}$ sections of formalin-fixed, paraffin-embedded tissue blocks were obtained for each case enrolled. Epitope retrieval was conducted prior to incubation of tissue sections with a panel of three primary antibodies (ready-to-use) from Novus
Biological: Survivin-1 (NB100-911 clone), Tag-72 (CC49 clone), and HERC5 (NBP-91985 clone). The immunostaining protocol for each antibody used was provided by the manufacturer. As chromogen, we used 3,3'diaminobenzidine (DAB), and brown staining was obtained. The final step was represented by counterstaining all slides with Mayer's Hematoxylin. Positive control was used for each antibody: Human testis for HERC5 antibody, malign melanoma for Survivin-1 antibody, and human prostate carcinoma for the Tag-72 antibody. Comparisons of the studied biomarker overexpression from HCC tissue samples with a matched non-HCC group of normal liver tissue specimens were made.

Statistical analysis. Quantitative variables such as mean \pm standard deviation (SD) and categorical variables are presented as percentages. The Student t-test and Mann-Whitney U test were used to identify differences between the two studied groups. The Chi-square test facilitated the comparison of categorical variables. The correlation between Survivin-1, Tag-72, and HERC5 overexpression and different HCC variables was performed using the Spearman rank correlation test. A multivariate logistic regression analysis detected the independent variables of HCC. The discriminative power of Survivin-1, Tag-72, and HERC5 overexpression was assessed using ROC curves. The predictive performance of biomarker overexpression was classically evaluated by the area under the ROC curve (AUC), sensitivity (Se), specificity (Sp), positive, and negative predictive values (PPV, NPV). SPSS 16.0 software (SPSS, Inc.) was used for statistical analysis. P-values $<0.05$ were considered statistically significant.

\section{Results}

Demographic, clinical and laboratory features of the HCC patients. According to demographics, we noted an evident predominance of male gender in the study group compared to the control group ( 17 vs. 25 male patients, $\mathrm{P}=0.023$ ). The age of the HCC patients was significantly older than that of the control group $(42.09 \pm 9.4$ vs. $59.2 \pm 5.9$ years, $\mathrm{P}=0.002)$. Laboratory results were various and without any statistical significance related to cytolysis $(30 \pm 11.67$ vs. $37.3 \pm 14.11 \mathrm{UI} / \mathrm{ml}, \mathrm{P}=0.067)$ but significantly different related to parameters of liver insufficiency such as albumin $(4.3 \pm 1.2$ vs. $2.3 \pm 1.4 \mathrm{~g} / \mathrm{dl}, \mathrm{P}<0.001)$, bilirubin $(1.9 \pm 0.5$ vs. $4.3 \pm 2.7 \mathrm{mg} / \mathrm{dl}, \mathrm{P}=0.002)$, and INR (International Normalized Ratio) $(1.4 \pm 0.8$ vs. $1.9 \pm 1.0, \mathrm{P}=0.026)$. AFP had values slightly above the normal upper limit in both HCC and controls, but levels $>180 \mathrm{ng} / \mathrm{ml}$ were more frequently encountered in HCC patients compared to the controls (204. $11 \pm 17.77$ vs. $308.56 \pm 44.01 \mathrm{ng} / \mathrm{ml}, \mathrm{P}=0.015)$. Jaundice was more regularly present in the HCC patients compared with the control (11 vs. 20 patients, $\mathrm{P}=0.044$ ) (Table I).

Comparison of IHC overexpression of Survivin-1, Tag-72, and HERC5 in liver tissue samples between HCC and controls. Statistical analysis using a multivariate linear regression tool was conducted to correlate the IHC overexpression of Survivin-1, Tag-72, and HERC5 and independent variables as age, sex, laboratory results, imaging and clinical features. The multivariate linear regression analysis revealed that Survivin-1, Tag-72, and HERC5 were significantly overexpressed upon 
Table I. Demographic, clinical, imaging and laboratory features of the HCC and control (benign tumor) group.

\begin{tabular}{|c|c|c|c|c|}
\hline & $\begin{array}{l}\text { Benign tumors } \\
\text { (control group) } \\
(\mathrm{N}=30) \\
\mathrm{n}(\%)\end{array}$ & $\begin{array}{l}\text { HCC group } \\
\text { (study group) } \\
(\mathrm{N}=30) \\
\mathrm{n}(\%)\end{array}$ & P-value & r-value \\
\hline Age, mean $\pm \mathrm{SD}$, years & $42.09 \pm 9.4$ & $59.2 \pm 5.9$ & 0.002 & 0.96 \\
\hline \multicolumn{5}{|l|}{ Sex } \\
\hline Male & $17(56.66)$ & $25(83.33)$ & 0.023 & 0.24 \\
\hline Female & $13(43.33)$ & $5(16.66)$ & 0.033 & -0.32 \\
\hline Urban & $12(40.00)$ & $15(50.00)$ & 0.051 & 0.70 \\
\hline \multicolumn{5}{|l|}{ Risk factors } \\
\hline Viral infection & $3(10.00)$ & $21(70.00)$ & 0.001 & 0.98 \\
\hline Alcohol abuse & $15(30.00)$ & $20(66.66)$ & 0.048 & 0.33 \\
\hline NASH/NAFLD & $5(16.66)$ & $11(36.66)$ & 0.042 & 0.34 \\
\hline Metabolic disease & $2(6.66)$ & $3(10.00)$ & 0.7 & 0.11 \\
\hline \multicolumn{5}{|l|}{ Clinical features } \\
\hline Hepatomegaly & $3(10.00)$ & $22(73.33)$ & 0.005 & 0.91 \\
\hline Jaundice & $11(36.66)$ & $20(66.66)$ & 0.044 & 0.59 \\
\hline Ascites & $1(3.33)$ & $16(53.33)$ & $<0.001$ & 0.99 \\
\hline Weight loss & $12(40.00)$ & $24(80.00)$ & 0.003 & 0.94 \\
\hline UDB & - & $7(23.33))$ & - & - \\
\hline \multicolumn{5}{|l|}{ Imaging features } \\
\hline Multifocal & $6(20.00)$ & $10(33.33)$ & 0.037 & 0.28 \\
\hline Portal vein thrombosis & $1(3.33)$ & $6(20.00)$ & 0.032 & 0.26 \\
\hline Ascites & $1(3.33)$ & $9(30.00)$ & 0.027 & 0.21 \\
\hline \multicolumn{5}{|l|}{ Laboratory results } \\
\hline \multirow[t]{2}{*}{ ALT UI/ml, mean $\pm \mathrm{SD} \uparrow$} & $30 \pm 11.67$ & $37.3 \pm 14.11$ & 0.067 & 0.58 \\
\hline & $10(33.33)$ & $23(76.66)$ & & \\
\hline \multirow[t]{2}{*}{ GGT UI/ml $\uparrow$} & $34.33 \pm 8.22$ & $71.54 \pm 6.99$ & 0.029 & 0.30 \\
\hline & $16(53.33)$ & $24(80.00)$ & & \\
\hline \multirow[t]{2}{*}{ Albumin g/dl $\downarrow$} & $4.3 \pm 1.2$ & $2.3 \pm 1.4$ & $<0.001$ & 0.99 \\
\hline & $1(3.33)$ & $22(73.33)$ & & \\
\hline \multirow[t]{2}{*}{ Bilirubin mg/dl $\uparrow$} & $1.9 \pm 0.5$ & $4.3 \pm 2.7$ & 0.002 & \\
\hline & $11(16.66)$ & $24(80.00)$ & & \\
\hline \multirow[t]{2}{*}{$\mathrm{INR} \uparrow$} & $1.4 \pm 0.8$ & $1.9 \pm 1.0$ & 0.026 & 0.44 \\
\hline & $10(33.33)$ & $12(40.00)$ & & \\
\hline AFP ng/ml $\uparrow$ & $12(40.00)$ & $23(76.66)$ & 0.011 & 0.29 \\
\hline \multirow[t]{2}{*}{$\geq 6 \mathrm{ng} / \mathrm{ml}$} & $6.92 \pm 2.6$ & $8.22 \pm 3.1$ & 0.051 & 0.70 \\
\hline & $11(18.60)$ & $14(46.66)$ & & \\
\hline \multirow[t]{2}{*}{$>180 \mathrm{ng} / \mathrm{ml}$} & $204.11 \pm 17.77$ & $308.56 \pm 44.01$ & 0.015 & 0.18 \\
\hline & $1(4.80)$ & $9(30.00)$ & & \\
\hline \multicolumn{5}{|l|}{ BCLC classification } \\
\hline A & - & 13 & - & - \\
\hline B & - & 11 & - & - \\
\hline $\mathrm{C}$ & - & 6 & - & - \\
\hline
\end{tabular}

HCC, hepatocellular carcinoma; NASH, nonalcoholic steatohepatitis; NAFLD, non-alcoholic fatty liver disease; ALT, alanine transaminase; GGT, $\gamma$-glutamyl transferase; AFP, $\alpha$-fetoprotein; BCLC, Barcelona Clinic Liver Cancer; INR, International Normalized Ratio. Laboratory results are expressed as the mean increased/decreased level (top value) and the number of patients (\%) with an increased/decreased level (lower data).

IHC analysis in HCC samples in patients older than 50 years $(\mathrm{P}=0.003, \mathrm{P}=0.006, \mathrm{P}=0.004$, respectively), male gender
( $\mathrm{P}=0.031, \mathrm{P}=0.004, \mathrm{P}=0.020$, respectively) patients with increased AFP over $180 \mathrm{ng} / \mathrm{dl}(\mathrm{P}=0.012, \mathrm{P}=0.004, \mathrm{P}=0.029$, 
Table II. Multivariate linear regression analysis to identify the correlation between overexpression of liver biomarkers and clinical, laboratory and imaging variables in HCC.

Liver tissue biomarker overexpression

\begin{tabular}{lccc}
\cline { 2 - 3 } Patient variables & $\begin{array}{c}\text { Survivin-1 } \\
\text { P-value (r) }\end{array}$ & $\begin{array}{c}\text { Tag-72 } \\
\text { P-value (r) }\end{array}$ & $\begin{array}{c}\text { HERC5 } \\
\text { P-value (r) }\end{array}$ \\
\hline Age, mean \pm SD, $>50$ years & $0.003(0.94)$ & $0.006(0.92)$ & $0.004(0.94)$ \\
Male gender & $0.031(0.55)$ & $0.004(0.96)$ & $0.020(0.70)$ \\
Bilirubin & $0.076(0.24)$ & $0.064(0.41)$ & $0.060(0.44)$ \\
INR & $0.055(0.54)$ & $0.088(0.27)$ & $0.059(0.52)$ \\
AFP $>180 \mathrm{ng} / \mathrm{ml}$ & $0.012(0.83)$ & $0.004(0.96)$ & $0.029(0.80)$ \\
Albumin $<3 \mathrm{mg} / \mathrm{dl}$ & $0.031(-0.66)$ & $0.021(0.72)$ & $0.003(0.94)$ \\
GGT & $0.059(0.72)$ & $0.055(0.51)$ & $0.030(0.48)$ \\
Portal thrombosis & $0.004(0.96)$ & $0.020(0.70)$ & $0.004(0.96)$ \\
Ascites & $0.002(0.98)$ & $0.004(0.96)$ & $0.019(0.82)$ \\
Hepatosplenomegaly & $0.060(0.74)$ & $0.003(0.94)$ & $0.039(0.59)$ \\
BCLC & & & $0.055(0.54)$ \\
A & $0.076(0.33)$ & $0.086(0.25)$ & $0.045(0.67)$ \\
B & $0.045(0.67)$ & $0.036(0.24)$ & $0.027(0.78)$ \\
C & $0.033(0.60)$ & $0.001(0.99)$ & \\
\hline
\end{tabular}

HCC, hepatocellular carcinoma; Tag-72, tumor-associated glyocoprotein; HERC5, HECT and RLD domain containing E3 ubiquitin protein ligase 5; GGT, $\gamma$-glutamyl transferase; AFP, $\alpha$-fetoprotein; BCLC, Barcelona Clinic Liver Cancer; INR, International Normalized Ratio.
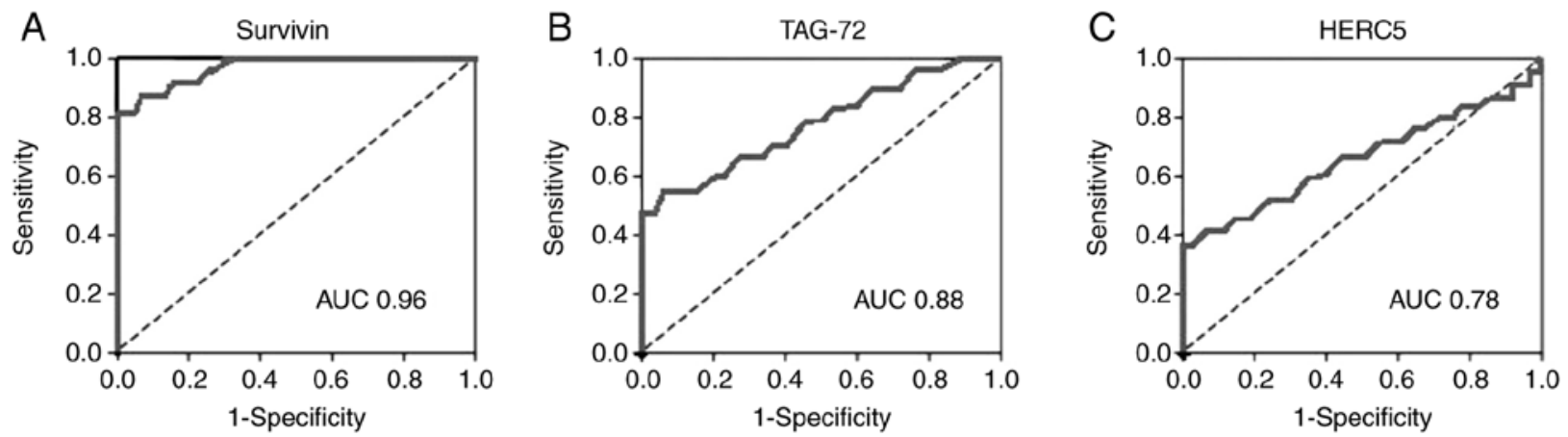

Figure 1. Area under the curve (AUC) for the liver tissue biomarker used for HCC diagnosis: (A) Survivin-1, (B) Tag-72, and (C) HERC5. HCC, hepatocellular carcinoma; Tag-72, tumor-associated glyocoprotein 72; HERC5, HECT and RLD domain containing E3 ubiquitin protein ligase 5.

respectively) and with low serum albumin $<3 \mathrm{mg} / \mathrm{dl}(\mathrm{P}=0.031$, $\mathrm{P}=0.021, \mathrm{P}=0.003$, respectively) as well as in patients with imaging features of portal thrombosis $(\mathrm{P}=0.004, \mathrm{P}=0.020$, $\mathrm{P}=0.004$, respectively) and ascites $(\mathrm{P}=0.002, \mathrm{P}=0.004$, $\mathrm{P}=0.019$, respectively) and in BCLC B class $(\mathrm{P}=0.045, \mathrm{P}=0.036$, $\mathrm{P}=0.045$, respectively) and $\mathrm{C}(\mathrm{P}=0.033, \mathrm{P}=0.001, \mathrm{P}=0.027$, respectively) classified patients (Table II). Overexpression of the studied biomarkers did not correlate positively with cytolysis and other cholestasis tests or with the remaining clinical or imaging features of HCC (Table II).

Diagnostic accuracy of Survivin-1, Tag-72 and HERC5 for HCC. Survivin-1 tissue biomarker had an AUC of $0.96[95 \%$ confidence interval (CI), 0.90-1.00] for the diagnosis of HCC, with $90.0 \%$ sensitivity, $100 \%$ specificity, $100 \% \mathrm{PPV}$, and $94.2 \%$ NPV for an optimal cut-off value of 0.3 (Fig. 1A and Table III). Tag-72 tissue biomarker had an AUC of 0.88 (95\% CI, 0.78-0.94), with $72.8 \%$ sensitivity, $95.6 \%$ specificity, $82.2 \%$ PPV, and $84 \%$ NPV for an optimal cut-off value of 0.3 (Fig. 1B and Table III). HERC5 had an AUC of 0.78 (95\% CI, 0.66-0.84), with $65 \%$ sensitivity, $86 \%$ specificity, $77.4 \% \mathrm{PPV}$, and $72.3 \% \mathrm{NPV}$ (Fig. 1C and Table III) for an optimal cut-off value of 0.3. AFP, still considered the gold standard biomarker used in clinical settings and recommended by the international guidelines for HCC management, had an AUC of 0.34 (95\% CI, 0.28-48) for the diagnosis of HCC, with $38.0 \%$ sensitivity, $66 \%$ specificity, $64 \%$ PPV, and $68.8 \%$ NPV for an optimal cut-off value of $180 \mathrm{ng} / \mathrm{dl}$ (Fig. 2). The diagnostic performance of Survivin-1, Tag-72 and HER-C5 tissue biomarkers for HCC characterization was superior to that of AFP, considered the gold standard biomarker used in clinical guidelines (Survivin-1: $\mathrm{Z}$ statistic $=2.911, \mathrm{P}=0.0039$; Tag-72: $\mathrm{Z}$ statistic $=2.789, \mathrm{P}=0.0049$, respectively; HERC5: $Z$ statistic $=2.844, P=0.0043$ ) and AFP assay alone $(\mathrm{Z}$ statistic $=5.022, \mathrm{P}<0.0001)($ Table IV). 
Table III. Accuracy parameters of Survivin-1, Tag-72 and HERC5 for HCC diagnosis.

\begin{tabular}{lccc}
\hline & Survivin-1 & Tag-72 & HERC5 \\
\hline AUC (95\% CI) & $0.96(0.90-1.00)$ & $0.88(0.78-0.94)$ & $0.78(0.66-0.84)$ \\
Accuracy (\%) & 97.2 & 80.4 & 75 \\
Sn $(\%)$ & 90 & 72.8 & 65 \\
Sp (\%) & 100.0 & 96.6 & 86 \\
PPV (\%) & 100.0 & 82.2 & 77.4 \\
NPV $(\%)$ & 94.2 & 84.0 & 72.3
\end{tabular}

Tag-72, tumor-associated glyocoprotein; HERC5, HECT and RLD domain containing E3 ubiquitin protein ligase 5; AUC, area under the ROC curve; Sn, sensitivity; Sp, specificity; PPV, positive predictive value; NPN, negative predictive value.

Table IV. Diagnostic performance of Survivin-1, Tag-72 and HER-C5 tissue biomarkers for HCC compared to gold standard AFP.

\begin{tabular}{lccc}
\hline Diagnostic performance & $\begin{array}{c}\text { Survivin-1 } \\
\text { z statistic (P-value) }\end{array}$ & $\begin{array}{c}\text { Tag-72 } \\
\text { z statistic (P-value) }\end{array}$ & $\begin{array}{c}\text { HERC5 } \\
\text { z statistic (P-value) }\end{array}$ \\
\hline AFP & $2.911(0.0039)$ & $2.789(0.0049)$ & $2.844(0.0043)$
\end{tabular}

Tag-72, tumor-associated glyocoprotein; HERC5, HECT and RLD domain containing E3 ubiquitin protein ligase 5; AFP, $\alpha$-fetoprotein.

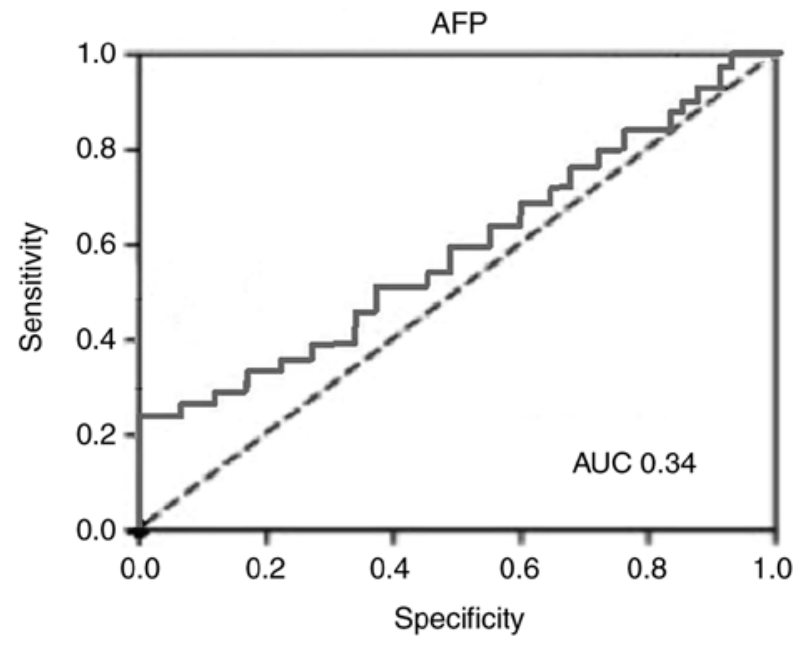

Figure 2. Area under the curve (AUC) for AFP used for HCC diagnosis. AFP, $\alpha$-fetoprotein; HCC, hepatocellular carcinoma.

\section{Discussion}

Immunohistochemistry represents a research tool with large applicability of monoclonal and polyclonal antibodies in detecting a specific antigen with a high potential for a positive diagnosis (16). This method is largely used to diagnose malignant tumors, but it presents an area of interest for numerous applications useful not only for positive and differential diagnosis but also to provide a research field in the attempt to identify prognostic markers for cancer evolution, to confirm the positive diagnosis of tumors with uncertain histogenesis, to predict the response to treatment and to identify or confirm certain infections $(7,17,18)$. Such biomarkers facilitate the efforts of researchers for a better understanding of HCC pathogeny, to provide more efficient therapies, and to improve disease prognosis. Epidemiology data confirm the persistent high global morbi-mortality rates for $\mathrm{HCC}$, which are more consistent in endemic areas for chronic viral infections, such as Asia, the Middle East, Mediterranean countries, South America, and Africa (19-22). The current guidelines use a single biomarker for HCC follow-up, this being $\alpha$-fetoprotein (AFP). The literature reports a low accuracy for AFP, and declines its role as a potent prognostic tool, thus new liver tissue biomarkers are being explored worldwide to improve HCC management (5). The difference between various etiopathogenic mechanisms involved in liver primary carcinogenesis makes it difficult to standardize a global panel of liver tissue biomarkers to simplify disease management. Using this scenario, having literature models from other studies conducted in different populations, we evaluated the expression of three liver tissue markers, aiming to confirm their overexpression in HCC tissue in patients from the Dobrogea area and to provide the background for further research for prognostic predictability or patient classification in risk groups. Our study demonstrated the same pattern of demographic, clinical, and laboratory features as the majority of published data, with a high prevalence of viral infections and alcohol abuse leading the risk factor background, and male gender and middle age, being the main characteristics of our patients. All liver tissue biomarkers explored provided a good accuracy for HCC diagnosis: $97.2 \%$ for Survivin-1, 80.4\% for Tag-72, and 75\% for HERC5, similar to the literature data $(10,12,13)$. AFP over the upper limit did not prove to have diagnostic or predictive value for HCC, similar to other literature articles (23-26). Still, values over $180 \mathrm{ng} / \mathrm{dl}$ were highly predictive, and they were found to be positively correlated with all biomarkers studied, Survivin-1, Tag-72, and HERC5 ( $r=0.83, r=0.96, r=0.80$, respectively). Our study results confirm the background hypothesis, indicating the 
overexpression of Survivin-1, Tag-72, and HERC5 as feasible biomarkers with which to diagnose HCC. Larger IHC studies should sustain the accuracy of the proposed tools before their introduction to international HCC management guidelines. Comparative study with other methods of diagnosis and prognostic evaluation used and other types of carcinomas, such as the study of neoangiogenesis or nuclear morphometry, can bring new useful data both in regards to diagnosis and in the prognosis of the disease $(27,28)$. Despite the importance of our study results, our work had limits due to the increased costs of study materials, a fact that influenced the number of samples evaluated by immunohistochemistry, a problem partially solved by the funds gained through university research grant competition.

In conclusion, our study results validate the overexpression of Survivin-1, Tag-72, and HERC5 as tissue biomarkers for HCC characterization in patients from our geographical region and could be standardized in the current HCC management guideline.

\section{Acknowledgements}

The present research was performed at the Research and Development Centre for the Morphologic and Genetic Study of Malignant Pathology from the 'Ovidius' University of Constanta, with the precious support of Professor Dr Mariana Aschie.

\section{Funding}

Financial support was obtained after attaining the 'Ovidius' University contest-July 2019 for research grants [POSCCE 2.2.1; Project ID: 1844; code SMIS: 48750; CEDMOG, contract 627/11.03.2014].

\section{Availability of data and materials}

The data were obtained from the HIPOCRATE file archive of the Emergency Hospital St. 'Apostle Andrew' of Constanta and CEDMOG archive (http://www.spitalulconstanta.ro/). Further information about the present study is available from the corresponding author upon reasonable request.

\section{Authors' contributions}

AIS, APS, GIB, VH, CN, LCP, FV, ISM and LM conceived and designed the study; ND, LCP, CB and FB collected the data. LCP, ND, CB, and FV analyzed the data; AIS, APS, CN and ISM validated the results. FB, CN, LCP and ND were responsible for original draft preparation; AIS, GIB, LCP, ND, ISM and VH were responsible for the final manuscript editing. AIS, APS, GIB and CN supervised the manuscript publication. All authors read and approved the final manuscript.

\section{Ethics approval and consent to participate}

The Ethics Committee of Emergency Clinical Hospital St Apostle Andrei Constanta approved the study following European and local regulations. Approval no. 32/22.11.2020.
Emergency Clinical Hospital St. Apostle Andrew from Constanta is a university hospital and all admitted patients sign an informed consent by which they agree that their data are available for academic and scientific purposes.

\section{Patient consent for publication}

Not applicable.

\section{Competing interests}

The authors declare that they have no competing interests.

\section{References}

1. Baecker A, Liu X, La Vecchia C and Zhang ZF: Worldwide incidence of hepatocellular carcinoma cases attributable to major risk factors. Eur J Cancer Prev 27: 205-212, 2018.

2. Liang Y, Chen J, Yu Q, Ji T, Zhang B, Xu J, Dai Y, Xie Y, Lin $\mathrm{H}$, Liang $\mathrm{X}$ and Cai $\mathrm{X}$ : Phosphorylated ERK is a potential prognostic biomarker for Sorafenib response in hepatocellular carcinoma. Cancer Med 6: 2787-2795, 2017.

3. Kudo M: Systemic Therapy for hepatocellular carcinoma: 2017 Update. Oncology 93 (Suppl 1): S135-S146, 2017.

4. Kudo M: Immuno-oncology in hepatocellular carcinoma: 2017 Update. Oncology 93 (Suppl 1): S147-S159, 2017.

5. Farinati F, Marino D, De Giorgio M, Baldan A, Cantarini M, Cursaro C, Rapaccini G, Del Poggio P, Di Nolfo MA, Benvegnù $\mathrm{L}$, et al: Diagnostic and prognostic role of alphafetoprotein in hepatocellular carcinoma: Both or neither? Am J Gastroenterol 101: 524-532, 2006.

6. Nishimoto S, Fukuda D, Higashikuni Y, Tanaka K, Hirata Y, Murata C, Kim-Kaneyama JR, Sato F, Bando M, Yagi S, et al: Obesity-induced DNA released from adipocytes stimulates chronic adipose tissue inflammation and insulin resistance. Sci Adv 2: e1501332, 2016.

7. El-Serag HB: Epidemiology of viral hepatitis and hepatocellular carcinoma. Gastroenterology 142: 1264-1273.e1, 2012.

8. Lee MH, Yang HI, Lu SN, Jen CL, Yeh SH, Liu CJ, Chen PJ, You SL, Wang LY, Chen WJ and Chen CJ: Hepatitis C virus seromarkers and subsequent risk of hepatocellular carcinoma: Long-term predictors from a community-based cohort study. J Clin Oncol 28: 4587-4593, 2010.

9. Jee SH, Ohrr H, Sull JW and Samet JM: Cigarette smoking, alcohol drinking, hepatitis B, and risk for hepatocellular carcinoma in Korea. J Natl Cancer Inst 96: 1851-1856, 2004.

10. Kannangai R, Wang J, Liu QZ, Sahin F and Torbenson M: Survivin-1 overexpression in hepatocellular carcinoma is associated with p53 dysregulation. Int J Gastrointest Cancer 35: 53-60, 2005.

11. Jin B, Wang X, Jin Y, Xia W, Chen B, Liu L, Chen Z, Hong L, $\mathrm{Du} \mathrm{W}$, Yan K, et al: Detection of serum gastric cancer-associated MG7-Ag from gastric cancer patients using a sensitive and convenient ELISA method. Cancer Invest 27: 227-233, 2009.

12. Chauhan SC, Vinayek N, Maher DM, Bell MC, Dunham KA, Koch MD, Lio Y and Jaggi M: Combined staining of TAG-72, MUC1, and CA125 improves labeling sensitivity in ovarian cancer: Antigens for multi-targeted antibody-guided therapy. J Histochem Cytochem 55: 867-875, 2007.

13. Xue F, Higgs BW, Huang J, Morehouse C, Zhu W, Yao X, Brohawn P, Xiao Z, Sebastian Y, Liu Z, et al: HERC5 is a prognostic biomarker for post-liver transplant recurrent human hepatocellular carcinoma. J Transl Med 13: 379, 2015.

14. Bernassola F, Karin M, Ciechanover A and Melino G: The HECT family of E3 ubiquitin ligases: Multiple players in cancer development. Cancer Cell 14: 10-21, 2008.

15. Torbenson MS, Ng IOL, Park YN, Roncalli M and Sakamoto M: Hepatocellular Carcinoma. In: WHO Classification of Tumours Editorial Board. Digestive system tumours. 5th edition. International Agency for Research on Cancer, Lyon, pp229-239, 2019.

16. Ramos-Vara JA and Miller MA: When tissue antigens and antibodies get along: Revisiting the technical aspects of immunohistochemistry-the red, brown, and blue technique. Vet Pathol 51: 42-87, 2014 
17. Torlakovic EE, Cheung CC, D'Arrigo C, Dietel M, Francis GD, Gilks CB, Hall JA, Hornick JL, Ibrahim M, Marchetti A, et al: Evolution of quality assurance for clinical immunohistochemistry in the era of precision medicine-part 2: Immunohistochemistry test performance characteristics. Appl Immunohistochem Mo Morphol 25: 79-85, 2017.

18. Bolocan A, Păduraru DN, Nițipir C, Hainăroșie R, Pițuru SM, Diaconu C, Suceveanu A and Stoian CD: Mixed adenoneuroendocrine carcinoma of the gastrointestinal tract-features, diagnosis, management and prognosis. Rom Biotechnol Lett 23: 14193-14202, 2018.

19. Gurtsevitch VE: Human oncogenic viruses: Hepatitis B and hepatitis $\mathrm{C}$ viruses and their role in hepatocarcinogenesis. Biochemistry (Mosc) 73: 504-513, 2008.

20. Donato F, Tagger A, Gelatti U, Parrinello G, Boffetta P Albertini A, Decarli A, Trevisi P, Ribero ML, Martelli C, et al: Alcohol and hepatocellular carcinoma: The effect of lifetime intake and hepatitis virus infections in men and women. Am J Epidemiol 155: 323-331, 2002

21. Ferenci P, Fried M, Labrecque D, Bruix J, Sherman M, Omata M, Heathcote J, Piratsivuth T, Kew M, Otegbayo JA, et al: World gastroenterology organisation guideline. Hepatocellular carcinoma (HCC): A global perspective. J Gastrointestin Liver Dis 19: 311-317, 2010.

22. Suceveanu AI, Pantea Stoian A, Mazilu L, Voinea F, Hainărosie R, Diaconu CC, Pituru S, Nitipir C, Badiu DC, Ceausu I and Suceveanu AP: Interferon-free therapy is not a trigger for hepatocellular carcinoma in patients with chronic infection with hepatitis C virus. Farmacia 66: 904-908, 2018.
23. Carr BI, Akkiz H, Üsküdar O, Yalçın K, Guerra V, Kuran S, Karaoğullarından Ü, Altıntaş E, Özakyol A, Tokmak S, et al: HCC with low- and normal-serum alpha-fetoprotein levels. Clin Pract (Lond) 15: 453-464, 2018.

24. Yang SL, Liu LP, Yang S, Liu L, Ren JW, Fang X, Chen GG and Lai PB: Preoperative serum $\alpha$-fetoprotein and prognosis after hepatectomy for hepatocellular carcinoma. Br J Surg 103: 716-724, 2016

25. An SL, Xiao T, Wang LM, Rong WQ, Wu F, Feng L, Liu FQ, Tian F and Wu JX: Prognostic significance of preoperative serum alpha-fetoprotein in hepatocellular carcinoma and correlation with clinicopathological factors: A single-center experience from China. Asian Pac J Cancer Prev 16: 4421-4427, 2015.

26. Omata M, Cheng AL, Kokudo N, Kudo M, Lee JM, Jia J, Tateishi R, Han KH, Chawla YK, Shiina S, et al: Asia-Pacific clinical practice guidelines on the management of hepatocellular carcinoma: A 2017 update. Hepatol Int 11: 317-370, 2017.

27. Ardeleanu V, Georgescu C, Frîncu LD, Frâncu LL and Vesa D: Angiogenesis as prospective molecular biology technique for cancer study. Rom Biotehnol Lett 19: 9637-9648, 2014.

28. Ardeleanu V, Francu L and Georgescu C: Neoangiogenesis. Assessment in esophageal adenocarcinomas. Indian J Surg 77 (Suppl 3): S971-S976, 2015 